\title{
Glycemic control of children and adolescents with type 1 diabetes improved after COVID-19 lockdown in Italy
}

\author{
Marco Marigliano $^{1}$ (1) $\cdot$ Claudio Maffeis $^{1}$
}

Received: 8 September 2020 / Accepted: 26 December 2020 / Published online: 2 February 2021

(c) Springer-Verlag Italia S.r.l., part of Springer Nature 2021

Keywords Type 1 diabetes $\cdot$ COVID-19 $\cdot$ CGM $\cdot$ Children $\cdot$ Adolescents $\cdot$ HbA1c

\section{Introduction}

The spread of severe acute respiratory syndrome coronavirus-2 (SARS-CoV-2) has reached pandemic dimensions worldwide [1]. To prevent the outbreak of the coronavirus disease (COVID-19), the lockdown was imposed in Italy on March 9, 2020, changing the daily routine of children and adolescents with type 1 diabetes (T1D).

The COVID-19 lockdown, with its effects on lifestyle changes, could have adversely affected long-term glycemic control [2]. On the other hand, subjects with T1D could have a more regular time schedule for insulin administration, higher control on glycemic values by their parents/caregivers. Therefore, COVID-19 lockdown could be a unique model to investigate how acute changes in lifestyle could have affected long-term glycemic control.

To the best of our knowledge, there are few data published on how lockdown could have influenced glucose control in pediatric patients with T1D. [3, 4] The aim of this study was to evaluate the impact of almost 3 months of COVID-19 lockdown on glycemic control in youths with T1D, analyzing metabolic variables and data from glucose sensors after the COVID-19 lockdown in comparison with the pre-lockdown period.

Managed by Massimo Federici .

Marco Marigliano

marco.marigliano@univr.it

1 Pediatric Diabetes and Metabolic Disorders Unit, Regional Center for Pediatric Diabetes, University City Hospital of Verona, P.le Stefani 1, 37126 Verona, Italy

\section{Material and methods}

This study included 233 children and adolescents with T1D aged 2-18 years enrolled at the Regional Center for Pediatric Diabetes of Verona (Italy). Inclusion criteria were: T1D duration $>12$ months; insulin therapy [multiple daily insulin injections (MDI) or continuous subcutaneous insulin infusion (CSII)]. Exclusion criteria were: diagnosis of eating disorders or other chronic diseases (i.e., thyroiditis, celiac disease). All the enrolled patients were under the same insulin regimen and using the same tool for measuring glucose levels [self-monitoring blood glucose (SMBG), intermittently scanned (isCGM, Abbott FreeStyle Libre ${ }^{\circledR}$ Glucose Monitoring System), or real-time Continuous Glucose Monitoring (rtCGM, Dexcom G6® CGM System)] before and after the COVID-19 lockdown. The study protocol was approved by the Institutional Ethics Committee of Verona Hospital, and all participants and their parents provided written informed consent.

Data were recorded two times: at the outpatient visit before and after the COVID-19 lockdown ( $\mathrm{T}_{0}$, January-February 2020; $T_{1}$, May-June 2020). Physical characteristics (height, weight, BMI, systolic and diastolic blood pressure), biochemical parameters (HbA1c), clinical data [diabetes duration, MDI or CSII, daily insulin doses and type of CGM used (isCGM or rtCGM)] were collected from the clinical chart. BMI values were standardized (BMI-SDS) using age and sex-specific median, standard deviation (SD) and power of the Box-Cox transformation based on WHO growth references. Two-week glucose sensor data were derived from AGP analysis, and several glucose metrics were analyzed: percentage of time below $54 \mathrm{mg} / \mathrm{dL}$, below $70 \mathrm{mg} / \mathrm{dL}$ (\%TBR), between 70 and $180 \mathrm{mg} / \mathrm{dL}$ (\%TIR), above $180 \mathrm{mg} / \mathrm{dL}$ (\%TAR), mean glucose, SD of the mean, coefficient of variation (\%CV) and glucose management indicator (GMI). All continuous variables were normally 
distributed and are reported as means $\pm \mathrm{SD}$; normal distribution was assessed by Shapiro-Wilk test. Categorical variables were presented as percentages. Differences between subjects before and after COVID-19 lockdown ( $\mathrm{T}_{0}$ vs. $\mathrm{T}_{1}$ ) were assessed by paired Student's $t$ test for continuous variables for the total sample and according to gender. The association between the improvement in glucose control $\left(\mathrm{T}_{1}-\mathrm{T}_{0}, \Delta \mathrm{HbA} 1 \mathrm{c}\right.$ and $\left.\Delta \% \mathrm{TIR}\right)$ and variables before the lockdown $\left(\mathrm{T}_{0}\right)$ was quantified by multiple regression analysis. Moreover, a binary logistic regression analysis was performed using HbA1c or \% TIR as dependent variable $(0=$ not improved; $1=$ improved $)$ and gender, age, duration of T1D, type of treatment (MDI or CSI), use or not of CGM and BMI-SDS at $\mathrm{T}_{0}$ as independent ones. Data were analyzed using SPSS version 20.0 software (SPSS, Chicago, IL; USA). A $p$ value $<0.05$ was considered to be statistically significant.

\section{Results}

Of the entire enrolled population, $38.6 \%$ were on CSII therapy, $15.0 \%$ on SMBG, $42.1 \%$ using isCGM and $42.9 \%$ rtCGM. Anthropometric characteristics, insulin therapy and glycemic control variables are presented in Table 1. No differences were found between $T_{0}$ and $T_{1}$ in body fat characteristics (BMI-SDS) and insulin therapy (total, basal, prandial, and per-kg insulin dose) in the entire population. However, a statistically significant difference $(p<0.05)$ between $\mathrm{T}_{0}$ and $\mathrm{T}_{1}$ was observed in BMI $\left(20.9 \pm 3.7 \mathrm{~kg} / \mathrm{m}^{2}\right.$ vs. $21.5 \pm 4.6 \mathrm{~kg} /$ $\left.\mathrm{m}^{2}\right)$, BMI-SDS $(0.58 \pm 0.84$ vs. $0.68 \pm 0.91)$ and basal insulin dose $(21.1 \pm 9.3 \mathrm{IU} /$ day vs. $22.3 \pm 10.2 \mathrm{IU} /$ day $)$ in females but not in males.

Analyzing isCGM and rtCGM data, no significant differences between $\mathrm{T}_{0}$ and $\mathrm{T}_{1}$ in $\%$ of time spent

Table 1 Characteristics of the entire study population and according to gender before lockdown $\left(\mathrm{T}_{0}\right)$ and after lockdown $\left(\mathrm{T}_{1}\right)$

\begin{tabular}{|c|c|c|c|c|c|c|c|c|c|}
\hline & \multicolumn{3}{|c|}{ Males $(n=131,55,7 \%)$} & \multicolumn{3}{|c|}{ Females $(n=102,44,3 \%)$} & \multicolumn{3}{|l|}{ Total $(n=233)$} \\
\hline & $\begin{array}{l}\text { Before lock- } \\
\text { down }\left(\mathrm{T}_{0}\right)\end{array}$ & $\begin{array}{l}\text { After lock- } \\
\text { down }\left(\mathrm{T}_{1}\right)\end{array}$ & $p$ & $\begin{array}{l}\text { Before lock- } \\
\text { down }\left(\mathrm{T}_{0}\right)\end{array}$ & $\begin{array}{l}\text { After lock- } \\
\text { down }\left(\mathrm{T}_{1}\right)\end{array}$ & $p$ & $\begin{array}{l}\text { Before lock- } \\
\text { down }\left(\mathrm{T}_{0}\right)\end{array}$ & $\begin{array}{l}\text { After lock- } \\
\text { down }\left(\mathrm{T}_{1}\right)\end{array}$ & $p$ \\
\hline Age (y) & $14.3(4.3)$ & $14.6(4.3)$ & $<0.001$ & $13.5(4.5)$ & $13.8(4.5)$ & $<0.001$ & $13.9(4.4)$ & $14.3(4.4)$ & $<0.001$ \\
\hline $\begin{array}{l}\text { T1D duration } \\
\text { (y) }\end{array}$ & $6.9(4.6)$ & $7.2(4.6)$ & $<0.001$ & $6.9(4.1)$ & $7.2(4.1)$ & $<0.001$ & $6.9(4.4)$ & $7.2(4.4)$ & $<0.001$ \\
\hline Height $(\mathrm{cm})$ & $159.2(20.2)$ & $160.5(19.6)$ & $<0.001$ & $151.1(19.7)$ & $151.6(19.4)$ & 0.395 & $155.7(20.4)$ & $156.6(20.0)$ & $<0.001$ \\
\hline Weight (kg) & $55.6(20.2)$ & $56.5(20.0)$ & $<0.001$ & $49.6(17.1)$ & $51.0(17.0)$ & $<0.001$ & $53.0(19.1)$ & $54.1(19.0)$ & $<0.001$ \\
\hline BMI & $21.0(3.8)$ & $21.1(3.8)$ & 0.373 & 20.9 & $21.5(4.6)$ & $<0.05$ & $20.9(3.8)$ & $21.3(4.2)$ & $<0.05$ \\
\hline BMI-SDS & $0.56(0.89)$ & $0.52(0.92)$ & 0.292 & $0.58(0.84)$ & $0.68(0.91)$ & $<0.05$ & $0.57(0.87)$ & $0.59(0.92)$ & 0.438 \\
\hline $\mathrm{SBP}(\mathrm{mmHg})$ & $107.2(11.1)$ & $112.9(12.0)$ & $<0.001$ & $106.3(10.4)$ & $108.7(11.4)$ & $<0.05$ & $106.8(10.8)$ & $111.1(11.9)$ & $<0.001$ \\
\hline $\mathrm{DBP}(\mathrm{mmHg})$ & $67.6(7.7)$ & $71.3(8.0)$ & $<0.001$ & $68.5(8.3)$ & $69.2(9.4)$ & 0.402 & $68.0(7.9)$ & $70.4(8.6)$ & $<0.001$ \\
\hline $\begin{array}{l}\text { Total insulin } \\
\text { (IU/d) }\end{array}$ & $46.3(23.6)$ & $46.8(21.4)$ & 0.519 & $42.2(19.8)$ & $42.9(17.8)$ & 0.462 & $44.5(22.1)$ & $45.1(20.0)$ & 0.330 \\
\hline $\begin{array}{l}\text { Basal insulin } \\
\text { (IU/d) }\end{array}$ & $21.7(12.0)$ & $21.8(10.9)$ & 0.742 & 21.1 & $22.3(10.2)$ & $<0.05$ & $21.4(10.9)$ & $22.0(10.6)$ & 0.087 \\
\hline $\begin{array}{l}\text { Prandial insu- } \\
\text { lin (IU/d) }\end{array}$ & $24.4(14.5)$ & $25.1(13.3)$ & 0.327 & $21.1(12.7)$ & $21.2(11.7)$ & 0.911 & $23.0(13.8)$ & $23.4(12.7)$ & 0.421 \\
\hline $\begin{array}{c}\text { Total insulin } \\
\text { (IU/Kg/d) }\end{array}$ & $0.80(0.25)$ & $0.81(0.21)$ & 0.497 & $0.84(0.25)$ & $0.84(0.24)$ & 0.785 & $0.82(0.25)$ & $0.83(0.23)$ & 0.507 \\
\hline HbA1c $(\%)$ & $7.78(0.89)$ & $7.40(0.80)$ & $<0.001$ & $7.88(0.78)$ & $7.49(0.86)$ & $<0.001$ & $7.82(0.84)$ & $7.44(0.83)$ & $<0.001$ \\
\hline GMI (\%) & $7.61(0.85)$ & $7.39(0.73)$ & $<0.001$ & $7.58(0.61)$ & $7.35(0.66)$ & $<0.001$ & $7.60(0.75)$ & $7.37(0.70)$ & $<0.001$ \\
\hline $\begin{array}{l}\text { Time }<54 \mathrm{mg} / \\
\mathrm{dl}(\%)\end{array}$ & 0.89 (1.37) & $0.99(1.90)$ & 0.556 & 1.05 (1.87) & $0.92(1.58)$ & 0.443 & $0.96(1.60)$ & $0.96(1.76)$ & 1.000 \\
\hline TBR $(\%)$ & $2.95(2.12)$ & $2.95(2.61)$ & 1.000 & $2.77(2.90)$ & $2.89(2.54)$ & 0.677 & $2.87(2.49)$ & $2.92(2.57)$ & 0.766 \\
\hline TIR (\%) & $53.3(16.7)$ & $57.8(15.9)$ & $<0.001$ & $51.7(13.1)$ & $58.2(14.1)$ & $<0.001$ & $52.6(15.2)$ & $58.0(15.1)$ & $<0.001$ \\
\hline TAR (\%) & $42.7(17.9)$ & $38.2(16.7)$ & $<0.001$ & $44.3(13.9)$ & 37.7 (14.6) & $<0.001$ & $43.4(16.2)$ & $38.0(15.8)$ & $<0.001$ \\
\hline $\begin{array}{l}\text { Mean glucose } \\
(\mathrm{mg} / \mathrm{dl})\end{array}$ & $179.0(35.3)$ & $169.8(30.2)$ & $<0.001$ & $178.1(25.3)$ & $168.2(26.5)$ & $<0.001$ & $178.6(31.2)$ & $169.1(28.6)$ & $<0.001$ \\
\hline SD of mean & $69.2(18.0)$ & $64.6(16.4)$ & $<0.001$ & $66.4(14.0)$ & $62.4(14.4)$ & $<0.001$ & $68.0(16.4)$ & $63.6(15.6)$ & $<0.001$ \\
\hline CV (\%) & $38.5(5.3)$ & $37.9(6.0)$ & 0.212 & $37.3(6.3)$ & $37.0(6.2)$ & 0.637 & 38.0 & $37.5(6.1)$ & 0.209 \\
\hline
\end{tabular}

Data are presented as mean and standard deviation in brackets, unless otherwise specified. Differences between subjects before and after COVID-19 lockdown ( $\mathrm{T}_{0}$ vs. $\mathrm{T}_{1}$ ) were assessed by paired Student's $t$ test for continuous variables for the total sample and according to gender. A $p$ value $<0.05$ was considered to be statistically significant 
below $54 \mathrm{mg} / \mathrm{dl}, \% \mathrm{TBR}$ and $\% \mathrm{CV}$ were found. A statistically significant improvement in glycemic control has been observed after lockdown $\left(\mathrm{T}_{0}\right.$ vs. $\left.\mathrm{T}_{1}\right)$ : a lower $\mathrm{HbA1c}(7.82 \pm 0.84$ vs. $7.44 \pm 0.83, p<0.001)$, GMI $(7.60 \pm 0.75$ vs. $7.37 \pm 0.70, p<0.001), \%$ TAR $(43.4 \pm 16.2$ vs. $38.0 \pm 15.8, p<0.001)$, mean glucose $(\mathrm{mg} / \mathrm{dl})(178.6 \pm 31.2$ vs. $169.1 \pm 28.6, p<0.001), \mathrm{SD}$ of the mean $(68.0 \pm 16.4$ vs. $63.6 \pm 15.6, p<0.001)$ and a higher \%TIR $(52.6 \pm 15.2$ vs. $58.0 \pm 15.1, p<0.001)$ (Fig. 1). Similar results were observed in males and females analyzed separately.

Independently from gender, age, duration of T1D, type of treatment (MDI or CSII), use or not of CGM and BMI-SDS at $\mathrm{T}_{0}$, the multiple regression analysis showed inverse correlations between the improvement in glucose control $(\Delta \mathrm{HbA} 1 \mathrm{c}$ and $\Delta \% \mathrm{TIR})$ and the HbA1c and the \%TIR measured before lockdown $\left(\mathrm{R}^{2}=0.123, p<0.001\right.$; $\mathrm{R}^{2}=0.130, p<0.001$, respectively) and the binary logistic regression analysis has confirmed these observations [HbA1c, OR:1.50 (95\% CI: 1.04-2.17; $p<0.05$ ); \% TIR, OR: 0.97 (95\%CI: 0.95-0.99; $p<0.05$ )].

\section{Discussion}

The lockdown due to the SARS-CoV-2 outbreak in Italy has been a massive challenge for the entire population. For children and adolescents with T1D, the forced change in lifestyle with reduction of physical activity but with more regularity in management of insulin therapy and more careful control on glycemic values by the patients and parents/ caregivers was associated with a better long-term glycemic control with a lower level of measured HbAlc and better glycemic metrics from data of isCGM and rtCGM (improved \% TIR, reduced GMI, \%TAR, mean glucose, SD).

Few data have been published on how COVID-19 lockdown has affected glycemic control in patients with T1D. In pediatric patients, the glycemic control in school and preschool children and in adolescents has been reported improved or at least not worsen but has been observed only before and during COVID-19 lockdown [3, 4].

Our data show that the glycemic improvement $(\Delta \mathrm{HbA} 1 \mathrm{c}$ and $\Delta \% \mathrm{TIR}$ ) has been observed in the whole population independently from gender, age, duration of T1D, BMISDS, type of treatment (MDI or CSII), the use or not of isCGM/rtCGM and that this improvement was inversely correlated with $\mathrm{HbA} 1 \mathrm{c}$ and \% TIR values measured just
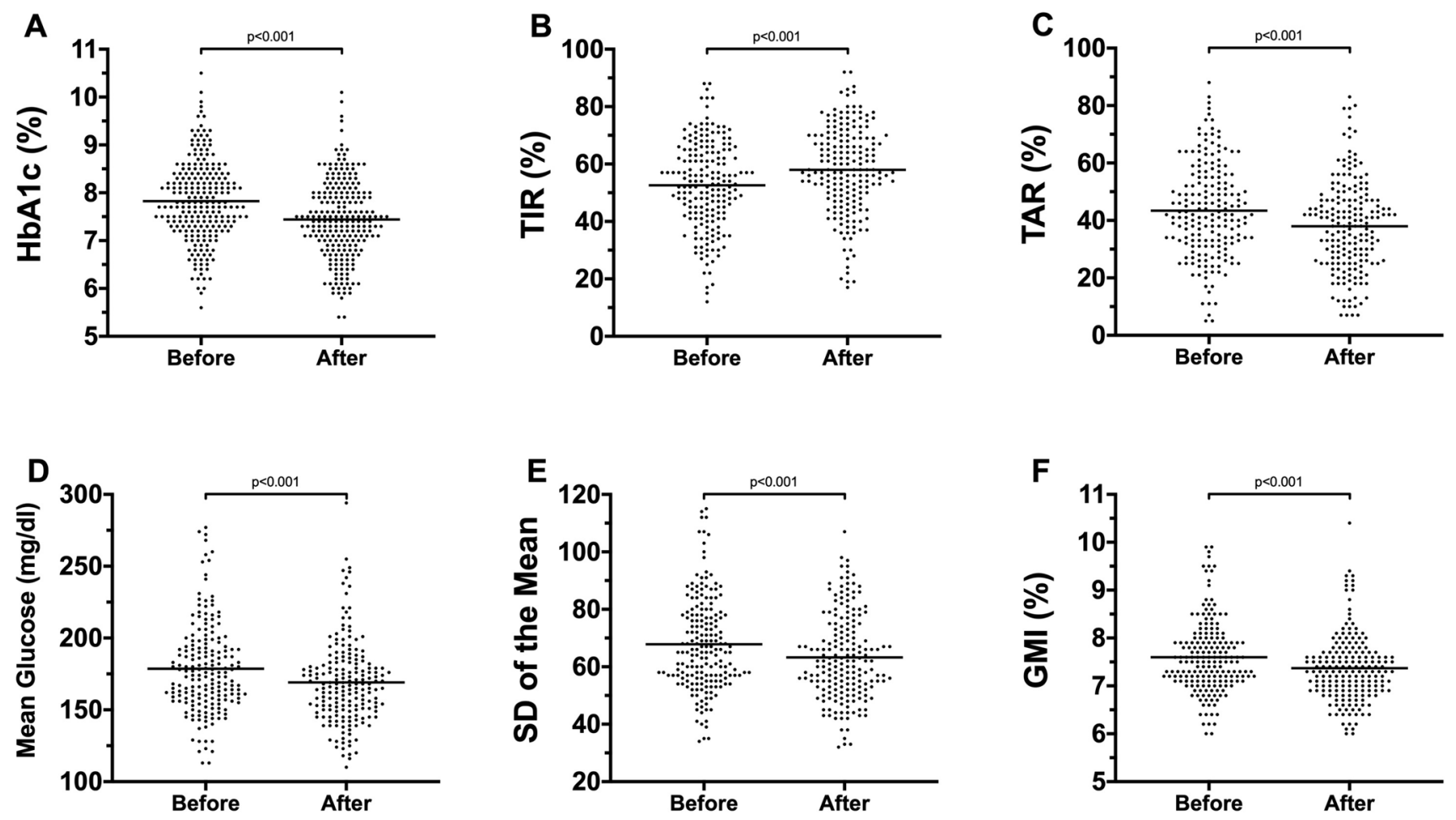

Fig. 1 Effect of COVID-19 lockdown on glycemic control in children and adolescents. The figure shows statistically significant reduction in HbA1c (A), \% of TAR (C), mean glucose (D), SD of the mean $(\mathbf{E})$ and glucose management indicator (GMI) (F) and a statistically significant improvement in \% of TIR (B) after almost three months of COVID-19 lockdown in Italy 
before the lockdown. Remarkably, the reduction in mean glucose, \%TAR and the increase in \% TIR was not associated with increased time in hypoglycemia (\% time $<54 \mathrm{mg}$ / $\mathrm{dl}$ and \%TBR) and with no significant increment in insulin dose. In sub-analysis according to gender, females showed a higher risk of weight gain with significantly higher BMI and BMI-SDS after three months of lockdown. The reasons of this result are unknown. In particular, we have no data on physical activity or nutritional habits that, likely, could contribute to explain the significant weight gain of females.

It could be hypothesized that, be forced at home due to the COVID-19 lockdown, has given to children and adolescents with T1D and to their parents/caregivers the opportunity to better take care of glucose control, maintaining a more regular and suitable schedule. Besides, the awareness that T1D could have worsened the outcomes of SARSCoV-2 may have improved patients' compliance with diabetes management [5].

In conclusion, we observed that glycemic control improved in children and adolescents with T1D after almost three months of COVID-19 lockdown. This observation suggests that modification of the lifestyle with slowing down routine activities and paying more attention to insulin therapy and glucose levels could have beneficial effects on T1D control.

Author contributions $\mathrm{MM}$ and CM designed the study, wrote and edited the manuscript. MM is the guarantor of this work and, as such, had full access to all the data in the study and take responsibility for the integrity and the accuracy of the data analysis.

Funding This research did not receive any specific grant from funding agencies in the public, commercial or not-for-profit sectors.

\section{Compliance with ethical standards}

Conflict of interest The authors declare that there is no conflict of interest.
Ethical standard statement All procedures performed in studies involving human participants were in accordance with the ethical standards of the institutional and/or national research committee and with the 1964 Helsinki Declaration and its later amendments or comparable ethical standards. The study was approved by the Ethics Committee of Verona Hospital (NUTRIMET/2016 /1010CESC).

Informed consent All parents and subjects signed an informed consent to participation.

\section{References}

1. Zhu N, Zhang D, Wang W et al (2020) A novel coronavirus from patients with pneumonia in China, 2019. N Engl J Med 382:727-733

2. Wang G, Zhang Y, Zhao J, Zhang J, Jiang F (2020) Mitigate the effects of home confinement on children during the COVID-19 outbreak. Lancet 395(10228):945-947. https://doi.org/10.1016/ S0140-6736(20)30547-X

3. d'Annunzio G, Maffeis C, Cherubini V et al (2020) Caring for children and adolescents with type 1 diabetes mellitus: italian society for pediatric and adolescent diabetes (ISPED) statements during COVID-19 pandemia. Diabetes Res Clin Pract. https://doi. org/10.1016/j.diabres.2020.108372

4. Tornese G, Ceconi V, Monasta L, Carletti C, Faleschini E, Barbi E (2020) Glycemic control in type 1 diabetes mellitus during COVID-19 quarantine and the role of in-home physical activity. Diabetes Technol Ther 22(6):462-467. https://doi.org/10.1089/ dia.2020.0169

5. Guo W, Li M, Dong Y et al (2020) Diabetes is a risk factor for the progression and prognosis of COVID-19. Diabetes Metab Res Rev. https://doi.org/10.1002/dmrr.3319

Publisher's Note Springer Nature remains neutral with regard to jurisdictional claims in published maps and institutional affiliations. 